\title{
17
}

\section{Our ordinary lives: Pathways to a more human-oriented linguistics}

\author{
John Newman
}

\section{Introduction ${ }^{1}$}

When one considers the range of data types, methods and research questions that characterise contemporary linguistics, it is clear that the field is diverse and ever expanding in ways that were hardly conceivable 100 , or even 50, years ago. One shift underlying many of these developments within linguistics has been the increased attention given to the speakers and writers of language. This shift is manifest in a variety of ways: how speakers interact in conversation, the cognitive processes accompanying acts of speaking and writing, the language used by speakers and writers in the form of language corpora, the role of the human body in shaping language (i.e. the idea of 'embodiment'), etc. It is clear that the idea that linguistics is primarily concerned with a system untethered to the speakers and writers of the language no longer holds sway in the way it once did.

1 It is a distinct pleasure to contribute to the present volume in honour of Anna Wierzbicka, whose body of linguistic research has been so uniquely original and insightful. Also, I thank the two anonymous reviewers for their helpful and thought-provoking comments on an earlier version of this chapter. 
The excerpt from Lass (1997: xviii) in (1) epitomises this earlier bias towards the language system that was dominant throughout much of the twentieth century:

\begin{abstract}
My main interest, and I suggest this ought to be one prime focus of the discipline, is in systems, not their users; the latter simply have to make do with what's historically presented to them, and cope with it when it changes ... This is not of course to say that the users aren't interesting; merely that they and their properties and actions belong to another subjectarea, not historical (or perhaps any) linguistics proper.
\end{abstract}

Although the immediate context of the above quote is the subfield of historical linguistics, Lass here advances the opinion that 'language users' (he means human beings), their properties and their actions perhaps do not belong to 'linguistics proper'. Even by 1997, however, speakers and writers of language, their intentions and their actions had come well into focus in many subfields of linguistics and the quote above must be seen as a decidedly conservative view of linguistics on the cusp of the twenty-first century. Croft's (2011: 1) statement in (2) offers, I believe, a more accurate reflection of contemporary practice in linguistics and how linguistic structure is viewed in the twenty-first century.

$$
\begin{aligned}
& \text { Language structure cannot be fully understood without } \\
& \text { situating it with respect to current theories of joint action, } \\
& \text { social cognition, conceptualization of experience, memory } \\
& \text { and learning, cultural transmission, and evolution, shared } \\
& \text { knowledge and practice in communities and demographic } \\
& \text { processes in human history. }
\end{aligned}
$$

In what follows I advocate two lines of research that reflect a more human-oriented kind of linguistics, in keeping with the larger trends in the field noted by Croft: (i) research that acknowledges the role of human experiential realities in the explication of language and (ii) a shift in research focus to the individual speaker and the agency of an individual.

\title{
2. Human experiential realities
}

One can identify an 'experientialist' orientation in disciplines that study human behaviour. An experientialist orientation is one that tries to understand human behaviour in terms of the human experience, as opposed 
to, say, understanding human behaviour in terms of abstract systems. One simple example of experientialist approaches in contemporary life would include the widespread acknowledgement that the 'user experience' is critical in evaluating and improving the delivery of modern technology. In academic fields such as anthropology and sociology, adopting the socalled 'insider's perspective', or an 'emic' perspective, may also be viewed as a type of experientialism.

An experientialist orientation in the study of human language can be seen in the writings of various linguists. ${ }^{2}$ For Lakoff (1987: xv, 266), the experientialist approach in linguistics represents an attempt 'to characterize meaning in terms of the nature and experience of the organisms doing the thinking', to be contrasted with an 'objectivist' approach in which meaning in human language is defined independently of the experience of humans. The label 'embodiment' is also applied to this kind of approach (Lakoff and Johnson 1999: 16-44), albeit with a slightly different nuance through the presence of the 'body' morpheme in this label (see Rohrer 2005 and Bergen 2015 for further discussion of the varieties of experientialism and embodiment). The field of Cognitive Linguistics has provided a natural home for experientialist approaches like that espoused by Lakoff, though the field has developed over the years to give more weight to the larger goal of reconciling the facts of language with the study of human and social cognition more generally (cf. Dancygier 2017). The quote in (3) is taken from the writings of Anna Wierzbicka and is indicative of the Natural Semantic Metalanguage (NSM) approach to the study of language which can also be understood as a kind of experientialism, as I use that term:

$$
\begin{aligned}
& \text { In natural language, meaning consists in human interpretation } \\
& \text { of the world. It is subjective, it is anthropocentric, it reflects } \\
& \text { predominant cultural concerns and culture-specific modes of } \\
& \text { social interaction as much as any objective features of the } \\
& \text { world 'as such'. (Wierzbicka 1988: 2) }
\end{aligned}
$$

2 A reviewer has drawn my attention to the extensive and insightful analysis of the English word experience in Wierzbicka (2010: Chapter 2) in which the author elucidates the Anglocentric semantics of the word and its non-universality as a concept. The reviewer poses the question: 'Can humans across the world be meaningfully studied through an English-specific keyword, and can we base a universal theory on untranslatable words such as "experience"?' I accept that there is a vagueness associated with terms such as human experience and experientialist and that they are not necessarily easily or precisely translatable into other languages. One would need to consult the works of individual authors to gain a more precise understanding of the ways in which a particular linguistic theory or framework is 'experientialist' (cf. in particular the discussion of varieties of experientialism in Rohrer 2005). 
The NSM approach undertakes semantic analysis through an analytical technique of reductive paraphrase that justifiably lays claim to 'conceptual authenticity' through its reliance on concepts that are familiar in the ordinary lives of speakers (Goddard and Wierzbicka 2014: 82). The concepts that are the building blocks of meanings in the NSM methodology are claimed to be 'simple, intelligible, and universally available words' (Wierzbicka 2010: 17) and are drawn from ordinary natural language. Relating aspects of language structure and use to culture is also very much in the spirit of an experientialist agenda and is something that Wierzbicka in particular has written about extensively (e.g. Wierzbicka 1992, 1997). In short, while Cognitive Linguistics and the NSM approach are clearly differentiated from each other and adopt quite different methods, they both see the human dimension as central to their cause and to their methods, in stark contrast to the position advocated by Lass and quoted above. While an experientialist orientation in contemporary linguistics is not confined to these two approaches, I have singled them out here since they have very explicitly acknowledged this element throughout their respective histories.

An additional way in which an experiential orientation may enter into the study of language is to seek out experientially salient aspects of human life as the object of study itself. In my own research I have chosen to make the verbs in (4), and their semantic equivalents in other languages, a focus of study and this is what I will elaborate on in what follows in this section. Clearly, these 'basic' verbs involve the human body in essential ways. The verbs are associated with a variety of body parts as elements that are salient in the semantics of the concept. Thus, we have the position of upper torso, buttocks and legs relevant to the semantics of sit, stand and lie; legs and even the body as a whole are relevant to come and go; eyes are relevant to see, just as ears are relevant to hear; the mouth and the digestive tract are relevant to eat and drink; hands and arms are relevant to give and take. The verbs make a linguistically satisfying set of concepts to study in the sense that they show a balance between being relatively static or dynamic in terms of their internal configuration.
(4) a. sit, stand, lie
b. come, go
c. see, hear
d. eat, drink
e. give, take 
As verbs that encode quite basic aspects of our everyday lives, they can be rewarding objects of study and for a variety of reasons. For a start, the verbs can be expected to function as key sources for conceptualising other aspects of our lives. In Euchee (Amerindian isolate, possibly Siouan), for example, the morphemes $c i$ 'sit, stay', fa 'stand' and ' $e$ 'lie' function as the suffixed articles occurring with singular inanimate nouns, and form the basis of what has been called a three-way 'gender' system (Watkins 1976: 35-36; Linn 2000: 364-70). This reliance on the 'sit/ stand/lie' conceptual set as a classificatory basis of inanimate nouns is an indication of the cardinal role these concepts play in our lives. Another instance of how the basicness of these concepts underlies unusual linguistic phenomena is the structural basicness associated with some of these verbs. The syntax associated with 'give' in some languages would be a case in point (cf. Newman 1996: 17-21). In Amele (Papuan, Roberts 1987), for example, affixes that would normally attach to verb stems such as tense, aspect, mood, verb agreement etc., appear merely as a string of affixes without any verb root in the 'give' construction. Compare the Amele three-place predicate 'show' example in (5a) with the 'give' example in $(5 b)$ :

(5)

a. Jo eu ihac-i-ad-ig-en.
house that show-PRED-2PL.IO-I SG.SUBJ-FUt
'I will show that house to you (plural).' (Roberts 1987: 69)
b. Naus Dege ho ut-en.
Naus Dege pig 3sG.IO-3SG.SUBJ.PAST
'Naus gave Dege the pig.' (Roberts 1987: 34)

The concepts behind the basic verbs in (4) are typically productive sources for many kinds of semantic extensions in languages. As far as semantic extensions are concerned, 'eat' is particularly remarkable in its productivity and has attracted much attention (cf. Newman 2009). Welmers' comments on the range of uses of Akan di 'eat' as shown in (6) point to something remarkable about this verb that even Welmers, writing as a structuralist linguist, found necessary to add to his description. 


$$
\begin{aligned}
& \text { I have attempted to sum up its [the Akan 'eat' verb's] uses } \\
& \text { under the general word for 'eat', but with other objects it } \\
& \text { refers among other things to using up or wasting money, } \\
& \text { taking a day off, having sexual relations with someone, } \\
& \text { accepting a bribe, inheriting goods, winning a victory, } \\
& \text { defeating an opponent, playing a game, holding an office, } \\
& \text { enduring suffering, making a bargain, living in some specified } \\
& \text { way, and so on at considerable length. A language has not } \\
& \text { been well studied until the nature of such semantic ranges, if not } \\
& \text { an exhaustive list of all recordable collocations, has been noted. } \\
& \text { (Welmers 1973: } 477 \text {, emphasis added) }
\end{aligned}
$$

Grammaticalisation is another kind of extension that can be found among the basic verbs. Reference was already made to how 'sit', 'stand' and 'lie' can function as a three-way basis for a classificatory system in languages. These same verbs may also give rise to aspect markers. In Manam, for example, soa? $i$ 'sit' is extended to express the progressive aspect, referring to an event that is in progress at the time of the speech act or the time of another event, as in (7a) (Lichtenberk 1983: 197-98). The Manam verb eno 'lie' also functions as an auxiliary, but in this case to indicate persistive aspect; that is, indicating that the event is performed persistently, as in (7b).
a. siresíre
di-bulabula-í-be
di-sóa?i
grass
3 PL.REALIS-Set.RDP-3SG.OBJ-and
3PL.REALIS-Sit
'They are burning grass.' (Lichtenberk 1983: 199)
b. i-pile-lá-be
i-éno
3SG.REALIS-speak-LIMITER-and
3SG.REALIS-lie
'He kept talking.' (Lichtenberk 1983: 200)

The verb 'give' is a rich source of grammaticalisations in the world's languages, as illustrated in the examples in (8) (cf. Heine and Kuteva 2002: 149-55 for a more complete overview). These examples illustrate extensions to manipulative/causative uses (8a), light verbs (8b), benefactive marker (8c), existential marker (8d), presentative marker (8e) and passive auxiliary (8f).
(8)

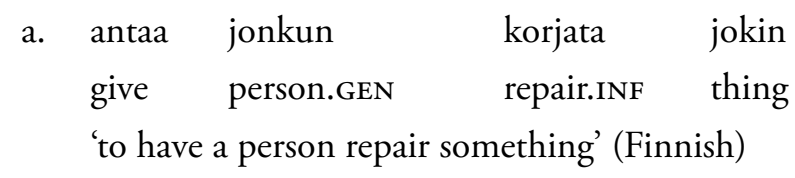


b. give the car a push/give it a try/give the ball a kick (English)

c. Po:pùk tèn siouphr̀u ?aoy khnom.

father buy books give me

'Father buys books for me.' (Cambodian, Jacob 1968: 141)

d. Es gibt viele Kinder in den Schulen.

it gives many children.ACC in the schools.DAT

'There are many children in the schools.' (German)

e. $\mathrm{Si}$ se da el caso ...

if REFL gives the event

'If the circumstance should arise ...' (Spanish)

f. E gët pensionnéiert.

he gives pensioned

'He's going to be pensioned off.' (Luxembourgish, Schanen 1987: 38)

This has been a necessarily selective illustration of the potential value of making ordinary everyday human experiences a focus of linguistic research. Nevertheless, I believe that the data provided are sufficient to show the range and diversity of linguistic phenomena associated with basic human experiences. I contend that the basicness of the experiences encoded by the verbs in (4) is a reason for the proliferation of extensions in usage of these verbs and their counterparts in other languages. They constitute natural starting points for linguistic research.

\section{Individuals}

Another direction for linguistics that leads to a more complete understanding of language and its use is to shift attention to language as experienced by individuals, as opposed to focusing only on the aggregate population. ${ }^{3}$ Linguistics has always acknowledged the shared social basis of language as essential to communication of course, as expressed by de Saussure (1959: 13-14): 'For Language [langue] is not complete in any speaker; it exists perfectly only within a collectivity'. A focus on the

3 An individual experience of language is arguably also evident in the NSM approach where both 'I' and 'you' perspectives ('I think ...', 'I feel ...' etc.) may occur alongside statements referring to what '(many) people' say, do, etc. 
aggregate behaviour is especially common in the current digital age, where large amounts of data across many individuals (as in a typical corpus) are analysed to ascertain the typical behaviour, or central tendency, of the aggregate of language users. Without denying the importance of the collective, or aggregate, population in the study of language, I nevertheless believe that a shift of attention to individual users is a worthwhile complement to this practice (cf. Newman 2017). In the remainder of this section I offer some examples of this shift of attention within linguistics.

As a preliminary observation, we might note that a greater acknowledgement of individual linguistic realities of speakers has parallels outside of linguistics that may be helpful in approaching the linguistic equivalent. An obvious parallel is literature where it is commonplace to study the corpus of an individual's output (e.g. John Keats), as well as the corpus of a selection of writers from a particular epoch (e.g. the Romantic period of English literature). The study of history has expanded from the study of whole societies or populations or eras (e.g. history of the First World War) to allow for the study of individuals participating in these events (e.g. tracking the life of an individual who experienced the First World War). Of most relevance in the present context, we see a shift of attention to individuals in the neighbouring discipline of psychology in the research agenda pursued most conscientiously in the pages of the Journal for Person-Oriented Research and summarised in (9), taken from the introductory article in the first issue of the journal: ${ }^{4}$

$$
\begin{aligned}
& \text { It is the aim of this issue to present and discuss approaches } \\
& \text { for bringing the individual back into focus in developmental } \\
& \text { psychology, as well as other areas of psychology. As far as } \\
& \text { possible, findings should be interpretable at the level of the } \\
& \text { single individual and they should be informative of patterns } \\
& \text { of individual functioning. (Bergman and Lundh 2015: 2) }
\end{aligned}
$$

Specifically, the person-oriented focus advocated by Bergman and Lundh is characterised by three foci: a pattern focus, a focus on the individual, a process focus (Bergman and Lundh 2015: 3).

There are indeed pockets of research in linguistics where an individual corpus or subcorpus is a familiar kind of data. Where there is a serious interest in human agency, then it would seem inevitable that it must

4 The Journal for Person-Oriented Research is freely available at: www.person-research.org/page3_1.php. 
be an individual, their personal circumstance and their particular personality that must be the object of study. Coupland's (2002) research on the stylistics of individual language use is an example of this kind of research. First language acquisition also comes to mind, with data on individual children readily available. Studies of individual children have certainly played their part in the research on first language acquisition, extending back to the meticulous documentation by Werner F. Leopold of his two daughters' simultaneous acquisition of German and English in the 1930s (cf. Lanza 2004: 18-23 for a summary and critical review of this work). Vihman, Ferguson and Elbert (1986: 29) offer a more contemporary opinion on the value of appreciating individual differences in language acquisition: 'In each of the areas investigated-phonetic tendencies, consonant inventory, and word selection-the prevalence of individual variation was the strongest lesson to be learned.' The extent of individual variation in language acquisition allows for, indeed points to the necessity of, thorough studies of individuals and their patterns of language acquisition (cf. the detailed case study of language acquisition in Theakston et al. 2012).

A more person-oriented agenda of research would include greater attention to documenting and attempting to explain changes over the lifespan of an individual, or at least phases of a lifespan, rather than just documenting the changes that are deemed to affect a whole community. Hinton (2015) studied the changes in a number of phonetic variables in the pronunciations over a lifetime of four public figures in British life: Her Majesty Queen Elizabeth II, Baroness Thatcher, Sir David Attenborough and David Dimbleby. Interestingly, Hinton found that the diachronic accent changes of these individuals over their lifetimes (1950s onwards) did not simply mirror sound changes that are known to have occurred in the norms of Received Pronunciation in this period of time. Changes observable in the speech of these individuals are not reducible to the overall intergenerational changes. Although public figures and celebrities are an obvious focus of interest in lifespan studies, the lives of ordinary speakers are equally revealing. To take just one example of such research, Bowie (2010) tracked changes in the realisation of post-vocalic $/ \mathrm{r} /$ and the aspiration of syllable-initial $/ \mathrm{m} /$ in 10 speakers (non-celebrities) across three to four decades of their lives. The data for this study came from a corpus of recorded religious addresses to conferences of The Church of Jesus Christ of Latter-day Saints (the Mormon Church), with the earliest longitudinal data collected in the years 1940, 1950 and 1960, and the 
latest data collected in the years 1970, 1980, 1990 and 2000. Bowie found that all 10 individuals exhibited some variation with respect to both of the variables investigated, but did not find any consistent pattern of change across all 10 speakers or from speaker to speaker. Once again, the variation in any one individual cannot be ascribed to simply ageing or changing community norms. Bowie suggests instead that the individual variation in this data reflects the reality of intra-speaker variation that exists in all phases of the lifespan:

All sociolinguistically competent adults, no matter how old,
have the ability to display different facets of their linguistic
identities whenever a need to do so is perceived to arise. In a
very real sense, we all possess the capacity to reinvent ourselves
linguistically at any time, at any age. (Bowie 2010: 66)

Alongside such lifespan accounts are more personal, autobiographical accounts of specific life changes and accompanying linguistic changes. Jhumpa Lahiri's (2015a, 2015b) writings about her experiences and feelings as she immersed herself more and more in an Italian-speaking world is a case in point. Lahiri's personal circumstances are unusual: she considers Bengali her mother tongue; she is an accomplished and celebrated author of English language novels and short stories (and winner of the 2000 Pulitzer Prize for Fiction); and she takes it upon herself to become a speaker and writer of Italian, which includes moving to Italy to live. Not surprisingly, her account of becoming a speaker and writer of Italian is an intensely personal, artistic expression rather than any kind of objective documentation, but it is no less interesting on account of its literary flavour. Arguably it is all the more interesting to a general audience precisely because of the literary nature of the writing.

Beyond simply observing individual differences in language behaviour, it is natural to inquire into the factors determining these differences beyond the usual ones of gender, age and social class. Dąbrowska (2015) provides an overview of some of these broadly 'experiential' factors and the interesting findings from this line of research. She reports on a number of studies that show the influence of education, occupational status and general reading skills on performance in carrying out linguistic tasks. This line of research points to quite different linguistic realities for individuals who fall into the 'low academic achievement' category compared with those in the 'high academic achievement' category, comparing their performance on tasks involving passive sentences, for example. 
At the very least, we need to make provision for case studies of individuals within linguistics, whether synchronic or diachronic, as a way of probing the lived realities of language users, to better understand all the factors that come into play in language use. This would mean incorporating into linguistics the methodologies of case studies, as advocated for the whole field of social sciences by Gerring (2017), as well as incorporating experimental methodologies that yield dense data on individuals and their processing of language (e.g. eye-tracking and event-related potential (or ERP) methodologies).

\section{Conclusion}

The suggestions offered here as directions for research in linguistics are unlikely to be considered as directions that all linguists would wish to make primary goals of their research. The allure of, and the undeniable intellectual rewards of, the intense study of language as an abstract system, far removed from the world of human speakers and writers, remains undeniably attractive to some linguists. Nevertheless, for some time now, the field of linguistics has been opening itself up to incorporate the study of language users, Lass' remarks cited above notwithstanding, and the field is richer because of that. Ultimately, languages are the products of human societies and human needs, and the more we acknowledge that truth the more complete our understanding of languages and language will be.

\section{References}

Bergen, Benjamin (2015). The cognitive foundations of language. In Ewa Dąbrowska and Dagmar Divjak (eds), Handbook of Cognitive Linguistics. Berlin: De Gruyter Mouton, 10-30.

Bergman, Lars R. and Lars-Gunnar Lundh (2015). Introduction. The personoriented approach: Roots and roads to the future. Journal for Person-Oriented Research 1 (1-2): 1-6. doi.org/10.17505/jpor.2015.01.

Bowie, David (2010). The ageing voice: Changing identity over time. In Carmen Llamas and Dominic Watt (eds), Language and Identities. Edinburgh: Edinburgh University Press, 55-66. 
Coupland, Nikolas (2002). Language, situation, and the relational self: Theorizing dialect-style in sociolinguistics. In Penelope Eckert and John R. Rickford (eds), Style and Sociolinguistic Variation. Cambridge University, 185-210. doi.org/10.1017/cbo9780511613258.012.

Croft, William (2011). Language structure in its human context: New directions for the language sciences in the twenty-first century. In Patrick Colm Hogan (ed.), The Cambridge Encyclopedia of the Language Sciences. Cambridge: Cambridge University Press, 1-11.

Dąbrowska, Ewa (2015). Individual differences in grammatical knowledge. In Ewa Dąbrowska and Dagmar Divjak (eds), Handbook of Cognitive Linguistics. Berlin: De Gruyter Mouton, 649-67.

Dancygier, Barbara (2017). Introduction. In Barbara Dancygier (ed.), The Cambridge Handbook of Cognitive Linguistics. Cambridge: Cambridge University Press, 1-10. doi.org/10.1017/9781316339732.001.

de Saussure, Ferdinand (1959). Course in General Linguistics. [English Translation of Cours de linguistique generale [1916], edited by Charles Bally and Albert Sechehaye with Albert Reidlinger, translated by Wade Baskin.] New York: Philosophical Library.

Gerring, John (2017). Case Study Research: Principles and Practices. Cambridge: Cambridge University Press.

Goddard, Cliff and Anna Wierzbicka (2014). Semantic fieldwork and lexical universals. Studies in Language 38 (1): 80-126. doi.org/10.1075/sl.38.1.03god.

Heine, Bernd and Tania Kuteva (2002). World Lexicon of Grammaticalization. Oxford: Oxford University Press.

Hinton, Martin (2015). Changes in Received Pronunciation: Diachronic case studies. Research in Language 13 (1): 21-37. doi.org/10.1515/rela-2015-0010.

Jacob, Judith M. (1968). Introduction to Cambodian. London: Oxford University Press.

Lahiri, Jhumpa (trans.) (2015a). In Other Words [translation of In Altre Parole by Ann Goldstein]. Knopf Doubleday Publishing Group.

Lahiri, Jhumpa (trans.) (2015b). Teach yourself Italian [translated from Italian by Ann Goldstein]. The New Yorker, 7 Dec: 30-36.

Lakoff, George (1987). Women, Fire, and Dangerous Things: What Categories Reveal About the Mind. Chicago: University of Chicago Press. 
Lakoff, George and Mark Johnson (1999). Philosophy in the Flesh: The Embodied Mind and Its Challenge to Western Thought. New York: Basic Books.

Lanza, Elizabeth (2004 [1997]). Language Mixing in Infant Bilingualism: A Sociolinguistic Perspective (corrected edition). New York: Oxford University Press.

Lass, Roger (1997). Historical Linguistics and Language Change. Cambridge: Cambridge University Press.

Lichtenberk, Frantisek (1983). A Grammar of Manam. Honolulu: University of Hawai'i Press.

Linn, Mary Sarah (2000). A Grammar of Euchee (Yuchi). Unpublished PhD dissertation, University of Kansas.

Newman, John (1996). Give: A Cognitive Linguistic Study. Berlin and New York: Mouton de Gruyter.

Newman, John (ed.) (2009). The Linguistics of Eating and Drinking. Amsterdam: John Benjamins.

Newman, John (2017). When individuals matter: Person-oriented research in contemporary linguistics. In Anastasia Makarova, Stephen M. Dickey, and Dagmar S. Divjak (eds), Each Venture a New Beginning: Studies in Honor of Laura A. Janda. Bloomington, Illinois: Slavica Publishers, 15-27.

Roberts, John (1987). Amele. Beckenham, Kent: Croom Helm.

Rohrer, Tim C. (2005). Embodiment and experientialism. In Dirk Geeraerts and Herbert Cuyckens (eds), The Handbook of Cognitive Linguistics. Oxford: Oxford University Press, 25-47.

Schanen, François (1987). Grundzüge einer Syntax des Lëtzebuergeschen: Die Verbalgruppe [Essentials of Luxembourgish syntax: The verbal group]. In Jean-Pierre Goudaillier (ed.), Aspekte des Lëtzebuergeschen [Aspects of Luxembourgish]. Hamburg: Helmut Buske Verlag, 3-90.

Theakston, Anna L., Robert Maslen, Elena V.M. Lieven, and Michael Tomasello (2012). The acquisition of the active transitive construction in English: A detailed case study. Cognitive Linguistics 23 (1): 91-128. doi.org/10.1515/ cog-2012-0004.

Vihman, Marilyn M., Charles A. Ferguson, and Mary Elbert (1986). Phonological development from babbling to speech: Common tendencies and individual differences. Applied Psycholinguistics 7 (1): 3-40. doi.org/10.1017/s014271 6400007165 . 
Watkins, Laurel J. (1976). Position in grammar: Sit, stand, lie. Kansas Working Papers in Linguistics 1: 16-41. doi.org/10.17161/kwpl.1808.702.

Welmers, William Everett (1973). African Language Structures. Berkeley, California: University of California Press.

Wierzbicka, Anna (1988). The Semantics of Grammar. Amsterdam: John Benjamins.

Wierzbicka, Anna (1992). Semantics, Culture, and Cognition: Universal Human Concepts in Culture-Specific Configurations. New York: Oxford University Press.

Wierzbicka, Anna (1997). Understanding Cultures through their Key Words: English, Russian, Polish, German, and Japanese. New York: Oxford University Press.

Wierzbicka, Anna (2010). Experience, Evidence, and Sense: The Hidden Cultural Legacy of English. Oxford Scholarship Online. doi.org/10.1093/acprof:oso/ 9780195368000.001.0001. 
This text is taken from Meaning, Life and Culture: In conversation with Anna Wierzbicka, edited by Helen Bromhead and Zhengdao Ye, published 2020 by ANU Press, The Australian National University,

Canberra, Australia.

doi.org/10.22459/MLC.2020.17 